\title{
Dietary profile of urban adult population in South India in the context of chronic disease epidemiology (CURES - 68)
}

\author{
Ganesan Radhika, Rangaswamy M Sathya, Anbazhagan Ganesan, Raghavan Saroja, \\ Parthasarathy Vijayalakshmi, Vasudevan Sudha and Viswanathan Mohan* \\ Madras Diabetes Research Foundation \& Dr. Mohan's Diabetes Specialities Centre, WHO Collaborating Centre \\ for Non-Communicable Diseases, International Diabetes Federation Centre of Education, 4 Conran Smith Road, \\ Gopalapuram, Chennai, India
}

Submitted 14 March 2009: Accepted 2 June 2010: First published online 12 August 2010

\begin{abstract}
Objective: Few dietary surveys have been done with reference to chronic diseases, such as diabetes, in India, which is considered to be the diabetes capital of the world. We report on the dietary intake of urban adults living in Chennai, South India.

Design: A population-based cross-sectional study.

Setting: A representative population of urban Chennai in southern India.

Subjects: The study population comprised 2042 individuals aged $\geq 20$ years selected from the Chennai Urban Rural Epidemiological Study (CURES). Dietary intake was measured using a validated and previously published interviewer-administered semi-quantitative meal-based FFQ.

Results: The mean daily energy intake was 10393 (SD 2347) kJ (male: 10953 (SD 2364) kJ $v$. female: 9832 (SD 233) kJ). Carbohydrates were the major source of energy (64\%), followed by fat (24\%) and protein (12\%). Refined cereals contributed to the bulk of the energy $(45 \cdot 8 \%)$, followed by visible fats and oils $(12 \cdot 4 \%)$ and pulses and legumes $(7 \cdot 8 \%)$. However, energy supply from sugar and sweetened beverages was within the recommended levels. Intake of micronutrient-rich foods, such as fruit and vegetable consumption $(265 \mathrm{~g} / \mathrm{d})$, and fish and seafoods $(20 \mathrm{~g} / \mathrm{d})$, was far below the FAO/WHO recommendation. Dairy and meat products intake was within the national recommended intake.

Conclusions: The diet of this urban South Indian population consists mainly of refined cereals with low intake of fish, fruit and vegetables, and all of these could possibly contribute to the risk of non-communicable diseases such as diabetes in this population.
\end{abstract}

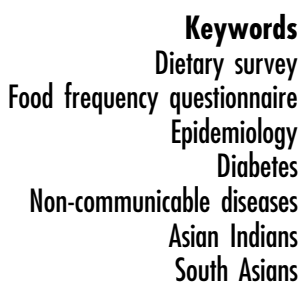

Keywords questionnaire idemiology diseases sian Indians South Asians
At the end of 20th century, India had rapid progress in controlling communicable diseases and the socioeconomic status of people has shown marked improvement. However, ageing of the population and altered lifestyles (unhealthy diets and physical inactivity) have contributed to the increase in the prevalence of chronic non-communicable diseases such as diabetes, obesity and $\mathrm{CVD}^{(1)}$. According to recent estimates, India leads the world with the largest number of persons with type 2 diabetes $(50 \cdot 8 \text { million })^{(2)}$. In all, $53 \%$ of all deaths and $44 \%$ of disability-adjusted life-years lost in India in 2005 could be attributed to chronic disease (including cancer, coronary artery disease, CVD, hypertension and diabetes) ${ }^{(3)}$.

The common factors with regard to diabetes and its rising prevalence rates are increased insulin resistance, stronger genetic factors and environmental factors, particularly those associated with urbanisation $^{(4)}$. Although genetic factors ${ }^{(5)}$ and physical inactivity ${ }^{(6)}$ have been shown to explain, at least in part, the diabetes epidemic, there is paucity of data on the dietary intake of the population. In many developing countries, food-related policies continue to focus only on undernutrition, and do not address the prevention of chronic diseases, which are primarily due to overnutrition ${ }^{(7,8)}$. Moreover, large national surveys such as National Sample Survey Organization do not provide an insight into the actual dietary intake of individuals ${ }^{(9)}$. There are recent data to show that the shifts in diet, activity and obesity are linked to the risk of non-communicable diseases, such as diabetes ${ }^{(10)}$.

There is an urgent need to understand the current dietary profile of the population to identify diet-related risk factors of chronic diseases such as diabetes in order to plan preventive strategies. The present study was undertaken to assess the dietary intake of an urban South Indian adult population. 


\section{Materials and methods}

\section{Sample selection}

Participants were recruited from the urban component of the Chennai Urban Rural Epidemiological Study (CURES), conducted on a representative population of Chennai (formerly Madras) in southern India, with a population of about 5 million. The methodology of the study has been published elsewhere ${ }^{(11)}$ and our website (http://www. drmohansdiabetes.com/mdrf/CURES.pdf) provides details of the sampling frame. Briefly, Chennai is divided into 155 corporation wards, representing a socio-economically diverse group. In Phase 1 of CURES, 26001 adults (aged $\geq 20$ years) from forty-six corporation wards were screened for diabetes by fasting capillary blood glucose using the systematic random sampling technique. Phase 2 of CURES deals with studies on prevalence of microvascular and macrovascular complications of diabetes.

In Phase 3 of CURES, every tenth participant recruited in Phase 1 ( $n$ 2600) was invited to our centre for detailed anthropometric measurements and biochemical tests and 2350 participants ( $90 \%$ response) took part. Of these, 2220 participated in the dietary assessment study; participants with a self-reported history of diabetes or CVD and those with unrealistic reported energy intake $(<2092 \mathrm{~kJ} / \mathrm{d}$ $(<500 \mathrm{kcal} / \mathrm{d})$ or $>17573 \mathrm{~kJ} / \mathrm{d}(>4200 \mathrm{kcal} / \mathrm{d}))^{(12)}$ were excluded. Thus, a total of 2042 participants (response rate: $87 \%$ ) were included for the present analysis.

\section{Dietary assessment}

Dietary intake was assessed using a previously validated and published interviewer-administered, meal-based, semi-quantitative FFQ containing 222 food items to estimate the usual food intake over the past year ${ }^{(13)}$. The interviews were conducted by nutritionists who were well trained in the methodology before any fieldwork commenced, and inter-interviewer agreement for the frequency of the consumption of foods was $95 \%$.

The FFQ consisted of a list of 222 food items that are normally consumed by the population. The food and beverages were categorised into the following thirteen food groups: (i) cereals (refined and whole); (ii) millets; (iii) pulses and legumes; (iv) dairy products; (v) tubers; (vi) fruit and vegetables (includes fruits, leafy vegetables, other vegetables and roots); (vii) meat and poultry; (viii) fish and seafood; (ix) eggs; (x) visible fats and oils; (xi) nuts and oilseeds; (xii) sugars (added in food preparation, non-alcoholic beverages, milk and malted beverages); and (xiii) alcoholic drinks.

Individuals were asked to estimate the usual frequency (number of times per $\mathrm{d} /$ week/month/year or never) and their usual serving size of the various food items in the FFQ. The respondents were also asked whether certain fruit and vegetables were consumed in season or year round and were then asked to provide the frequency of intake during that period and the amount. Data on the average seasonal availability (in months) of such fruit and vegetables were obtained from twenty-five local wholesale vendors and agricultural institutes. These values were used to convert reported seasonal intake into average intake throughout the year. Common household measures, such as household cups, bowls, ladles, spoons, wedges and circles of different diameters, and a visual atlas of different sizes of fruit (small, medium and large) were shown.

The FFQ also had separate open-ended questions such as type of fats and oils used for regular cooking and removal of skin from chicken, and blank rows to capture missing food items. A detailed description of this FFQ and the data on reproducibility and validity have been published elsewhere ${ }^{(13)}$. The validity of the FFQ has been documented by comparison with six $24 \mathrm{~h}$ recalls collected at 2-month intervals for a period of 1 year covering all seasons and included weekdays and weekends to capture variability. The energy-adjusted de-attenuated Pearson correlation coefficient between the FFQ estimate and the average of six $24 \mathrm{~h}$ recalls was 0.70 for refined cereals, 0.65 for pulses and legumes, 0.60 for roots and tubers, 0.69 for meat and poultry, 0.58 for fish and seafoods, $0 \cdot 61$ for dairy products, 0.71 for sugars, 0.28 for fruit and vegetables, 0.62 for visible fats and oils and 0.61 for nuts and oilseeds ${ }^{(14)}$.

Responses to individual food items and macronutrients were converted to average daily intake for each participant using an in-house EpiNu India ${ }^{\circledR}$ database and software (Nutritional Epidemiology, Food and Nutrient database, version $1 \cdot 0$, Chennai, India), developed and launched by the Department of Foods, Nutrition and Dietetics Research of the Madras Diabetes Research Foundation. This database contains comprehensive data for 1500 recipes (both commercial and non-commercial) and over sixty nutrients ${ }^{(13,15)}$.

\section{Statistical analysis}

All analyses were conducted using the Statistical Package for Social Sciences statistical software package version $12 \cdot 0$ (SPSS Inc., Chicago, IL, USA). The analysis was conducted on data stratified by age and gender, wherever appropriate. The mean of each variable (age (years), height $(\mathrm{cm})$, weight $(\mathrm{kg})$, BMI $\left(\mathrm{kg} / \mathrm{m}^{2}\right)$, waist circumference $\left.(\mathrm{cm})\right)$ was reported and compared for the descriptive characteristics. Values were expressed as the mean (SD). One-way ANOVA was used to compare continuous variables, and the $\chi^{2}$ test was used to compare the proportions among groups. All tests of significance were two-tailed and a $P$ value of $<0.05$ was considered significant.

\section{Results}

Out of a total of 2350 participants, 2042 were included in the present analysis, which included 917 (44.9\%) men and $1125(55 \cdot 1 \%)$ women, giving a male-to-female ratio 
of $0 \cdot 82$. The total mean food intake estimated by adding the respective mean estimates of all food items was $1467 \mathrm{~g} / \mathrm{d}$. The mean energy intake was estimated to be 10393 (SD $2347) \mathrm{kJ} / \mathrm{d}$ of which $64 \%$ was derived from carbohydrates, $24 \%$ from fat sources and $12 \%$ from protein.

Table 1 shows the clinical characteristics and food consumption in men and women. The mean age and BMI was 40.7 (SD 12.8) years and 23.9 (SD 4.5$) \mathrm{kg} / \mathrm{m}^{2}$, respectively. Mean consumption values for cereals, pulses and legumes, dairy products, tubers, fruit and vegetables

Table 1 Clinical characteristics and food consumption in men and women ( $n$ 2042)

\begin{tabular}{|c|c|c|c|c|}
\hline & \multicolumn{4}{|c|}{ Consumption $(\mathrm{g} / \mathrm{d})$} \\
\hline & \multicolumn{2}{|c|}{ Men ( $n$ 917) } & \multicolumn{2}{|c|}{ Women ( $n 1125$} \\
\hline & Mean & SD & Mean & SD \\
\hline Age (years) & $41 \cdot 1$ & $13 \cdot 2$ & $40 \cdot 2$ & $12 \cdot 4$ \\
\hline BMI $\left(\mathrm{kg} / \mathrm{m}^{2}\right)$ & $23 \cdot 2$ & $4 \cdot 1$ & $24 \cdot 5$ & $4 \cdot 8$ \\
\hline \multicolumn{5}{|l|}{ Food groups $(\mathrm{g} / \mathrm{d})$} \\
\hline Cereals (refined) & $345 \cdot 1$ & $108 \cdot 3$ & $315 \cdot 2$ & $100 \cdot 1$ \\
\hline Cereals (whole) & $41 \cdot 9$ & $37 \cdot 8$ & $37 \cdot 1$ & $32 \cdot 9$ \\
\hline Millets (refined and whole) & $6 \cdot 8$ & $9 \cdot 7$ & $6 \cdot 6$ & $9 \cdot 5$ \\
\hline Pulses and legumes & $55 \cdot 8$ & $21 \cdot 1$ & $49 \cdot 9$ & $19 \cdot 6$ \\
\hline Dairy products* & $412 \cdot 1$ & $239 \cdot 9$ & $375 \cdot 1$ & $220 \cdot 3$ \\
\hline Tubers & $134 \cdot 8$ & $49 \cdot 3$ & $127 \cdot 3$ & $54 \cdot 7$ \\
\hline Fruit and vegetablest & 273.5 & $110 \cdot 1$ & $256 \cdot 4$ & $119 \cdot 8$ \\
\hline Meat and poultry & $55 \cdot 1$ & $47 \cdot 3$ & $44 \cdot 2$ & $39 \cdot 0$ \\
\hline Fish and seafoods & $21 \cdot 4$ & $12 \cdot 9$ & $18 \cdot 6$ & $11 \cdot 5$ \\
\hline Eggs & $12 \cdot 2$ & $11 \cdot 6$ & $14 \cdot 9$ & $11 \cdot 0$ \\
\hline Visible fats and oils & $35 \cdot 6$ & $13 \cdot 4$ & $31 \cdot 6$ & $11 \cdot 5$ \\
\hline Nuts and oilseeds & $25 \cdot 1$ & $16 \cdot 1$ & $21 \cdot 0$ & $12 \cdot 3$ \\
\hline Sugars $\ddagger$ & $53 \cdot 1$ & 28.9 & $42 \cdot 6$ & $15 \cdot 9$ \\
\hline Alcoholई & $35 \cdot 0$ & $67 \cdot 9$ & $-\|$ & $-\|$ \\
\hline
\end{tabular}

*Dairy products include milk, cheese, yoghurt and buttermilk.

tFruit and vegetables include fruits, leafy vegetables, other vegetables and roots.

łIncluded sugars added in food preparation, non-alcoholic beverages (synthetic juices, Pepsi, Cola, etc.) and milk and malted beverages.

\$Alcohol includes beer, gin, spirits, wine (all) and country liquor.

IIWomen never consumed alcohol. (this includes fruit, leafy vegetables, other vegetables and roots), meat and poultry, visible fats and oils and sugars were significantly higher in men than women, whereas eggs were higher in women.

The mean intake of various food groups and the percentage contribution of each food group to the daily energy and macronutrients are presented in Table 2 . There was high consumption of refined cereals, which alone contributed $330 \cdot 2 \mathrm{~g} / \mathrm{d}$ and provided $45 \cdot 8 \%$ of total energy intake and $64.5 \%$ of the total daily carbohydrates. Polished white rice (parboiled) was the most frequently consumed and ranked as top cereal followed by idli (fermented steamed cake, made out of parboiled rice and black gram dhal batter), dosa (shallow fried pancake made of parboiled rice and black gram dhal batter) and wheat in the form of chapathi (flat bread). The consumption of whole cereals was low and provided $2 \cdot 7 \%$ of total energy and $3.6 \%$ of carbohydrate intake, whereas millet consumption (mean: $6.7 \mathrm{~g} / \mathrm{d}$ ) was also negligible and contributed only $1.9 \%$ of the total energy intake. Pulses and legumes contributed $52.9 \mathrm{~g} / \mathrm{d}$ and provided $7.8 \%$ of total energy, $17 \cdot 2 \%$ of the daily protein and $2 \cdot 1 \%$ of total fat intake. The mean consumption of tubers was $131 \cdot 1 \mathrm{~g} / \mathrm{d}$ and contributed $3.0 \%$ to total energy intake. Potato was the most frequently consumed tuber with reported intake of $40 \mathrm{~g} / \mathrm{d}$ and was either shallow fried or stir fried.

The average intake of vegetables (leafy, other vegetables and roots) was $152.6 \mathrm{~g} / \mathrm{d}$ and that of fruits was $112 \cdot 4 \mathrm{~g} / \mathrm{d}$, whereas the mean intake of fruit juices was $44 \mathrm{~g} / \mathrm{d}$. Of the latter, citrus fruit juices provided $19 \cdot 7 \mathrm{~g} / \mathrm{d}$ and other fruit juices provided $24 \cdot 2 \mathrm{~g} / \mathrm{d}$. The total mean consumption of fresh fruit and vegetables in the study population as reported earlier was $265 \mathrm{~g} / \mathrm{d}$, and $90.9 \%{ }^{(15)}$ of the population consumed less than the $\mathrm{FAO} / \mathrm{WHO}$ recommended value of $400 \mathrm{~g}$ of fruit and vegetables per day. The fruit varieties consumed included bananas

Table 2 Mean intake of various food groups contributing to energy and macronutrients in the study population aged $\geq 20$ years $(n 2042)$

\begin{tabular}{|c|c|c|c|c|c|c|}
\hline \multirow[b]{2}{*}{ Food groups $(\mathrm{g} / \mathrm{d})$} & \multicolumn{2}{|c|}{ Mean consumption $(\mathrm{g} / \mathrm{d})$} & \multirow[b]{2}{*}{ Energy intake (\%) } & \multirow[b]{2}{*}{ Carbohydrate intake (\%) } & \multirow[b]{2}{*}{ Protein intake (\%) } & \multirow[b]{2}{*}{ Fat intake (\%) } \\
\hline & Mean & SD & & & & \\
\hline Cereals (refined) & $330 \cdot 2$ & $104 \cdot 2$ & $45 \cdot 8$ & $64 \cdot 5$ & $30 \cdot 9$ & $2 \cdot 7$ \\
\hline Cereal (whole) & 39.5 & $35 \cdot 4$ & $2 \cdot 7$ & 3.6 & $3 \cdot 2$ & 0.5 \\
\hline Millets & $6 \cdot 7$ & $9 \cdot 6$ & $1 \cdot 9$ & $1 \cdot 3$ & $0 . \overline{62}$ & 0.9 \\
\hline Pulses and legumes & $52 \cdot 9$ & $20 \cdot 4$ & $7 \cdot 8$ & $8 \cdot 4$ & $17 \cdot 2$ & $2 \cdot 1$ \\
\hline Tubers & $131 \cdot 1$ & $52 \cdot 0$ & $3 \cdot 0$ & $4 \cdot 4$ & $2 \cdot 3$ & $0 \cdot 3$ \\
\hline Fruit and vegetables* & $265 \cdot 0$ & $115 \cdot 0$ & $4 \cdot 3$ & $5 \cdot 2$ & $5 \cdot 1$ & $1 \cdot 2$ \\
\hline Dairy productst & $393 \cdot 6$ & $230 \cdot 1$ & $9 \cdot 5$ & $3 \cdot \overline{8}$ & $15 \cdot 1$ & $21 \cdot \overline{4}$ \\
\hline Meat and poultry & $49 \cdot 7$ & $20 \cdot 2$ & $2 \cdot 5$ & 0.002 & 13.9 & $3 \cdot 1$ \\
\hline Fish and seafoods & $20 \cdot 0$ & $12 \cdot 2$ & $1 \cdot 1$ & 0.03 & $6 \cdot 8$ & 0.8 \\
\hline Visible fats and oils & 33.6 & $12 \cdot \overline{5}$ & $12 \cdot 4$ & 0.003 & 0.02 & $53 \cdot 3$ \\
\hline Eggs & $13 \cdot 6$ & $11 \cdot 3$ & 0.9 & 0.04 & $2 \cdot 4$ & $2 \cdot 7$ \\
\hline Nuts and oilseeds & $23 \cdot 1$ & $14 \cdot 2$ & $3 \cdot 1$ & 0.6 & $1 \cdot 7$ & $10 \cdot 6$ \\
\hline Sugarsł & $47 \cdot 9$ & $22 \cdot 4$ & $4 \cdot 4$ & $6 \cdot 8$ & 0.94 & $0 \cdot 85$ \\
\hline Alcohols & $35 \cdot 0$ & $67 \cdot 9$ & $1 \cdot 7$ & $0 \cdot 1$ & $0 \cdot 1$ & 0.001 \\
\hline
\end{tabular}

*Fruit and vegetables include fruits, leafy vegetables, other vegetables and roots.

tDairy products include milk, cheese, yoghurt and buttermilk.

flncluded sugars added in food preparation, non-alcoholic beverages (synthetic juices, Pepsi, Cola, etc.) and milk and malted beverages.

$\S$ Alcohol includes beer, gin, spirits, wine (all) and country liquor. 
$(22 \cdot 0 \mathrm{~g} / \mathrm{d})$, guava $(21 \cdot 1 \mathrm{~g} / \mathrm{d})$, citrus fruits $(20 \cdot 3 \mathrm{~g} / \mathrm{d})$, mango $(17 \cdot 6 \mathrm{~g} / \mathrm{d})$, sapota $(8 \cdot 4 \mathrm{~g} / \mathrm{d})$, grapes $(8 \cdot 3 \mathrm{~g} / \mathrm{d})$, papaya $(6.7 \mathrm{~g} / \mathrm{d})$, apple $(5 \cdot 0 \mathrm{~g} / \mathrm{d})$ and pomegranate $(3 \cdot 8 \mathrm{~g} / \mathrm{d})$.

Dairy products contributed $393.6 \mathrm{~g} / \mathrm{d}$ providing $9.5 \%$ of daily energy intake, $15 \cdot 1 \%$ of protein and $21 \cdot 4 \%$ of total fat intake. Among dairy products 'buttermilk' (diluted curd or yoghurt) contributed the highest intake of $132.5 \mathrm{~g} / \mathrm{d}$, followed by curd or yoghurt $(78.7 \mathrm{~g} / \mathrm{d})$. Only $1.6 \%$ of the population consumed cheese. Plain milk as such was the least consumed $(25.9 \% ; n$ 530) choice as against coffee ( $n$ 1323) and tea with milk ( $n$ 1051), the most popular choices. Moreover, $<1 \%$ fat milk was reported by only $2 \%$ of the participants, whereas $3-4 \%$ fat milk was reported by $87 \%$ of the participants. With respect to hot beverages such as tea and coffee, the average intake was $24.3 \mathrm{~g} / \mathrm{d}$, which provided $0.6 \%$ of energy, $0.7 \%$ of carbohydrate, $0.9 \%$ of protein and $0.25 \%$ of fat. None reported black coffee, tea and iced tea.

The mean intake of meat and poultry was $49.7 \mathrm{~g} / \mathrm{d}$ and this provided $2.5 \%$ of the daily energy intake, $13.9 \%$ of protein and $3 \cdot 1 \%$ total fat intake. Among meat and poultry, chicken in the form of gravy/sauce was most frequently consumed and reported at $20 \mathrm{~g} / \mathrm{d}$ followed by fried chicken $(10 \mathrm{~g} / \mathrm{d})$. Among chicken consumers, $60 \%$ of the participants did not remove the skin. Of the entire study population, $37 \cdot 4 \%$ preferred mutton in the form of gravy and $18.7 \%$ preferred it in fried form. Low consumption of fish and seafood was noted with an average value of $20 \cdot 0 \mathrm{~g} / \mathrm{d}$, and this provided only $1 \cdot 1 \%$ of the total energy and $6.8 \%$ of protein. The mean intake of eggs was $13.6 \mathrm{~g} / \mathrm{d}$ and the most preferred preparation of egg in the population was an 'omlette'.

The mean intake of visible fats and oils (including those used in cooking and added at the table) was $33.6 \mathrm{~g} / \mathrm{d}$ and accounted for $12 \cdot 4 \%$ of the total energy intake. The type of oil most commonly reported by participants and used in cooking and/or frying of foods was vegetable sunflower oil (64\%), followed by palm oil (21\%), groundnut oil ( $8 \%)$, gingelly $(6 \%)$ and coconut oil (1\%). Visible fats and oils had the highest contribution to the total fat intake, providing $53.3 \%$ of daily fat intake.

The mean intake of sugar (added in food preparation, non-alcoholic, milk and malted beverages) was $47 \cdot 9 \mathrm{~g} / \mathrm{d}$ and this contributed $4 \cdot 4 \%$ of the total energy and $6 \cdot 8 \%$ of carbohydrate intake. Added sugar in hot beverages such as coffee, tea, malted beverages and plain milk contributed $22 \cdot 8 \mathrm{~g} / \mathrm{d}$ (excluding non-alcoholic beverages). The consumption of sweets was, on average, $40 \mathrm{~g} / \mathrm{d}$ and the most frequently consumed sweet in the population was laddoo, an Indian sweet prepared from fried bengal gram dhal balls and sugar coated (56.9\%) followed by sheera/kesari (semolina, sugar and ghee; 52.8\%) and payasam (vermicelli/rice/sago boiled with milk and sugar; $47 \cdot 8 \%)$ and the consumption of desserts such as 'soufflé or custard' was reported by only $4 \cdot 8 \%$ of the population.

The average intake of non-alcoholic drinks (soft drinks and pre-packed juices) was $25 \cdot 2 \mathrm{~g} / \mathrm{d}$ and this provided $0 \cdot 4 \%$ of the energy and $0.6 \%$ of the carbohydrates. The average intake of alcoholic drinks was $35.0 \mathrm{~g} / \mathrm{d}$, as reported by men only (1.7\% of the total energy intake). Spirits (brandy) and country liquor were the most widely consumed alcoholic drinks ( $11.6 \%$ of consumers), followed by beer $(3 \cdot 2 \%$ of consumers) and wine ( $0.5 \%$ of consumers); however, alcoholic drink such as toddy was not reported in the present study by any of the participants.

Table 3 shows the mean consumption of various food groups by age group category. Significant difference $(P<0 \cdot 001)$ in the consumption of refined cereals, tubers, fruit and vegetables (this includes fruit, leafy vegetables, other vegetables and roots), fish, eggs and sugar was

Table 3 Mean consumption of various food groups by age group ( $n$ 2042)

\begin{tabular}{|c|c|c|c|c|c|c|c|c|c|}
\hline \multirow[b]{3}{*}{ Food groups $(\mathrm{g} / \mathrm{d})$} & \multicolumn{8}{|c|}{ Consumption (g/d) } & \multirow[b]{3}{*}{$P$ for trend } \\
\hline & \multicolumn{2}{|c|}{$\begin{array}{c}\text { 20-29 years } \\
(n 525)\end{array}$} & \multicolumn{2}{|c|}{$\begin{array}{c}\text { 30-39 years } \\
(n 613)\end{array}$} & \multicolumn{2}{|c|}{$\begin{array}{c}\text { 40-49 years } \\
(n 449)\end{array}$} & \multicolumn{2}{|c|}{$\begin{array}{c}\geq 50 \text { years } \\
(n 455)\end{array}$} & \\
\hline & Mean & SD & Mean & SD & Mean & SD & Mean & SD & \\
\hline Cereals (refined) & $328 \cdot 9$ & $98 \cdot 7$ & $346 \cdot 0$ & $102 \cdot 8$ & $335 \cdot 0$ & $112 \cdot 4$ & $310 \cdot 9$ & $102 \cdot 8$ & $0 \cdot 001$ \\
\hline Cereals (whole) & $37 \cdot 2$ & $34 \cdot 1$ & $41 \cdot 0$ & $35 \cdot 6$ & $40 \cdot 6$ & $34 \cdot 9$ & $39 \cdot 1$ & $37 \cdot 1$ & $0 \cdot 446$ \\
\hline Millets (refined and whole) & $7 \cdot 5$ & $7 \cdot 7$ & $7 \cdot 2$ & $11 \cdot 7$ & $5 \cdot 5$ & $8 \cdot 4$ & $6 \cdot 7$ & $10 \cdot 6$ & 0.367 \\
\hline Pulses and legumes & $51 \cdot 9$ & $19 \cdot 1$ & $54 \cdot 2$ & $21 \cdot 3$ & $54 \cdot 9$ & $22 \cdot 0$ & $50 \cdot 7$ & $19 \cdot 2$ & $0 \cdot 496$ \\
\hline Tubers & $142 \cdot 1$ & $49 \cdot 0$ & $134 \cdot 7$ & $52 \cdot 5$ & $136 \cdot 1$ & $55 \cdot 5$ & $111 \cdot 2$ & $51 \cdot 7$ & $<0.0001$ \\
\hline Fruit and vegetables* & $279 \cdot 9$ & $79 \cdot 2$ & $262 \cdot 8$ & $125 \cdot 3$ & $268 \cdot 8$ & $135 \cdot 5$ & $248 \cdot 3$ & $120 \cdot 1$ & $<0.0001$ \\
\hline Dairy productst & $352 \cdot 5$ & $211 \cdot 0$ & $400 \cdot 1$ & $229 \cdot 6$ & $419 \cdot 7$ & $235 \cdot 0$ & $402 \cdot 0$ & $244 \cdot 9$ & $<0.0001$ \\
\hline Meat and poultry & $50 \cdot 5$ & $17 \cdot 0$ & $59 \cdot 5$ & $28 \cdot 7$ & $46 \cdot 9$ & $21 \cdot 3$ & $41 \cdot 8$ & $13 \cdot 9$ & $<0.0001$ \\
\hline Fish and seafoods & $23 \cdot 8$ & $13 \cdot 2$ & $19 \cdot 9$ & $11 \cdot 1$ & $17 \cdot 2$ & $12 \cdot 4$ & $18 \cdot 9$ & $12 \cdot 0$ & $<0.0001$ \\
\hline Eggs & $16 \cdot 3$ & $11 \cdot 8$ & $14 \cdot 7$ & $11 \cdot 2$ & $12 \cdot 4$ & $10 \cdot 7$ & $11 \cdot 0$ & $11 \cdot 4$ & $<0.0001$ \\
\hline Nuts and oilseeds & $22 \cdot 5$ & $12 \cdot 3$ & $25 \cdot 1$ & $17 \cdot 4$ & $23 \cdot 2$ & $13 \cdot 8$ & $21 \cdot 6$ & $13 \cdot 4$ & 0.091 \\
\hline Sugarsł & $62 \cdot 7$ & $14 \cdot 6$ & $55 \cdot 3$ & $28 \cdot 6$ & $46 \cdot 9$ & $25 \cdot 5$ & $26 \cdot 6$ & $21 \cdot 0$ & $<0.0001$ \\
\hline Alcohol§ & $23 \cdot 1$ & $31 \cdot 4$ & $42 \cdot 8$ & $105 \cdot 5$ & $34 \cdot 4$ & 53.9 & $39 \cdot 8$ & $81 \cdot 1$ & 0.361 \\
\hline
\end{tabular}

*Fruit and vegetables include fruits, leafy vegetables, other vegetables and roots.

tDairy products include milk, cheese, yoghurt and buttermilk.

†Included sugars added in food preparation, non-alcoholic beverages (synthetic juices, Pepsi, Cola, etc.) and milk and malted beverages.

§Alcohol includes beer, gin, spirits, wine (all) and country liquor. 
Table 4 Comparison of urban (Chennai city) dietary intake in the year 1997 (CUPS; $n$ 403) and 2005 (CURES present study) in the study population aged $\geq 20$ years $(n$ 2042)

\begin{tabular}{|c|c|c|c|c|}
\hline & \multicolumn{4}{|c|}{ Mean consumption $(\mathrm{g} / \mathrm{d})$} \\
\hline & \multicolumn{2}{|c|}{$\begin{array}{l}\text { CUPS (1997) } \\
\quad(n \text { 403) }\end{array}$} & \multicolumn{2}{|c|}{$\begin{array}{l}\text { CURES (2005) } \\
\quad(n \text { 2042) }\end{array}$} \\
\hline & Mean & SD & Mean & SD \\
\hline Age (years) & $49 \cdot 0$ & $13 \cdot 0$ & $40 \cdot 7$ & $12 \cdot 8$ \\
\hline $\mathrm{BMI}\left(\mathrm{kg} / \mathrm{m}^{2}\right)$ & $21 \cdot 5$ & $4 \cdot 3$ & $23 \cdot 9$ & $4 \cdot 5$ \\
\hline Waist circumference $(\mathrm{cm})$ & $69 \cdot 5$ & $18 \cdot 4$ & $84 \cdot 8$ & $12 \cdot 0$ \\
\hline \multicolumn{5}{|l|}{ Food groups $(g / d)$} \\
\hline Cereals & $277 \cdot 8$ & $100 \cdot 8$ & $369 \cdot 0$ & $106 \cdot 1$ \\
\hline Pulses and legumes & $29 \cdot 4$ & $12 \cdot 3$ & $52 \cdot 7$ & $20 \cdot 3$ \\
\hline Leafy vegetables & $37 \cdot 0$ & $33 \cdot 5$ & $38 \cdot 2$ & $22 \cdot 3$ \\
\hline Other vegetables & $113 \cdot 2$ & $54 \cdot 4$ & $89 \cdot 4$ & $25 \cdot 7$ \\
\hline Roots and tubers & $54 \cdot 7$ & $37 \cdot 9$ & $156 \cdot 2$ & $76 \cdot 8$ \\
\hline Fruits & $50 \cdot 4$ & $39 \cdot 0$ & $112 \cdot 4$ & $42 \cdot 8$ \\
\hline Non-veg (meat, fish and poultry) & $30 \cdot 9$ & $10 \cdot 5$ & $83 \cdot 3$ & $45 \cdot 4$ \\
\hline Visible fats and oils & $30 \cdot 1$ & $10 \cdot 9$ & $33 \cdot 6$ & $11 \cdot 9$ \\
\hline Nuts and oilseeds & $9 \cdot 4$ & $7 \cdot 1$ & $23 \cdot 0$ & $13 \cdot 9$ \\
\hline Sugars* & $11 \cdot 7$ & $6 \cdot 1$ & $22 \cdot 8$ & $15 \cdot 3$ \\
\hline \multicolumn{5}{|l|}{ Nutrients } \\
\hline Energy (kcal) & 1782 & 409 & 2484 & 561 \\
\hline Energy (kJ) & 7456 & 1711 & 10393 & 2347 \\
\hline Protein (\%E) & $11 \cdot 4$ & $1 \cdot 2$ & $12 \cdot 1$ & $1 \cdot 7$ \\
\hline Fat $(\% \mathrm{E})$ & $29 \cdot 4$ & $3 \cdot 9$ & $23 \cdot 9$ & $4 \cdot 9$ \\
\hline Carbohydrate (\%E) & $58 \cdot 2$ & $5 \cdot 9$ & $63 \cdot 8$ & $6 \cdot 6$ \\
\hline Dietary fibre $(\mathrm{g})$ & $37 \cdot 0$ & $9 \cdot 2$ & $34 \cdot 7$ & $10 \cdot 3$ \\
\hline
\end{tabular}

CUPS, Chennai Urban Population Study; CURES, Chennai Urban Rural Epidemiological Study; \%E, percentage of energy.

*Included sugars added only in food preparation, so as to compare with CUPS study.

observed among the age categories. No significant difference was observed for whole cereals, millets and pulses and legumes among the age groups.

Table 4 compares the dietary intake of the Chennai population in 1997 with the present study carried out in 2005. Intake was higher in CURES than Chennai Urban Population Study (CUPS) for all major food groups such as cereals, pulses, fruits, roots and tubers, non-vegetarian foods and sugars.

Consumption of cereals, pulses, other vegetables, fats and oils, sugars and dairy products increased with improvement in education $(P<0 \cdot 0001)$. No such trends were observed in the case of total fruit and vegetables and fish and seafood. However, when expressed as a percentage of food energy, carbohydrate $(P<0 \cdot 0001)$ intake was higher among the low literacy group, whereas fat intake $(P<0 \cdot 0001)$ was higher with the higher education level (data not shown).

\section{Discussion}

The present study is, to our knowledge, the first to address the dietary profile of an urban South Indian population using a validated FFQ in the context of noncommunicable diseases. Overall, the study indicates that the diet of urban South Indians is high in cereals, particularly refined, and low in fish, fruit and vegetables, compared to the FAO/WHO recommendations ${ }^{(7)}$. However, meat products ${ }^{(16)}$, sugar and sweetened beverages ${ }^{(7)}$ were within the recommended intake for the prevention of chronic diseases. The consumption of dairy products is higher than the suggested dietary guidelines of $300 \mathrm{~g} / \mathrm{d}$ based on the Nutrient Requirements and Recommended Dietary Allowances for Indians (1989, Indian Council of Medical Research ${ }^{(16)}$. These findings are in contrast with the Western ${ }^{(17)}$ and Chinese ${ }^{(18)}$ populations, whose dietary pattern is characterised by a high intake of fatty meat and sugar-rich sweetened beverages, which have been identified as risk factors for obesity, type 2 diabetes and CVD. Evidence from our previous studies has shown that high intake of refined cereals (high glycaemic index) ${ }^{(14)}$, glycaemic $\operatorname{load}^{(19,20)}$ and low fruit and vegetable intake ${ }^{(15)}$ are positively associated with all components of the metabolic syndrome and risk of type 2 diabetes $^{(20)}$ in the present population.

In mid-1990s, the National Nutrition Monitoring Bureau and India Nutrition Policy indicated that at the aggregate national level, the total energy intake was $<9623 \mathrm{~kJ} / \mathrm{d}$ $(<2300 \mathrm{kcal} / \mathrm{d})^{(21)}$ compared to the RDA of $10146 \mathrm{~kJ} / \mathrm{d}$ $(2425 \mathrm{kcal} / \mathrm{d}$ ) for a sedentary man (measured by $24 \mathrm{~h}$ recall). However, there are inter-state differences in energy intake ${ }^{(21)}$. An earlier study from the Centre (CUPS) ${ }^{(2)}$ conducted in 1997 had shown energy intake of $7456 \mathrm{~kJ} / \mathrm{d}$ $(1782 \mathrm{kcal} / \mathrm{d}$; measured by FFQ), while in the present study, an intake of $10393 \mathrm{~kJ} / \mathrm{d}(2484 \mathrm{kcal} / \mathrm{d})$ was observed among the present Chennai urban participants, predominantly leading a sedentary lifestyle ( $75 \%$ of the participants were physically inactive $)^{(20)}$. Although the energy intake seems 
to be higher in the present study, methodological constraints and differences in sampling frames limit further interpretation of this finding.

Moreover, a recent national survey has reported that the share of cereals in total consumption expenditure has fallen from $15 \%$ to $10 \%$ in urban India, partly due to the decline in the cost of cereals ${ }^{(21,23)}$. But this trend masks a marked shift away from the so-called coarse and higher-fibre grains to rice and wheat, which are usually refined $^{(10,24)}$. Thus, the reduction of total cereal intake resulted in increased energy density due to considerable loss of beneficial dietary fibre and contributed to half of the dietary energy $(45 \cdot 8 \%)^{(14)}$, which also coincides with the modernisation and increase of rice mills (seven modern rubber-roll sheller mills in 1963 in India compared to 35088 in 1999) to improve the rice yield ${ }^{(25)}$. Consumption of whole grains in this population is $39.5 \mathrm{~g} / \mathrm{d}$ and this intake was similar to the average American consumption $^{(26)}$.

Evidence from a review of 250 observational studies suggests that increased consumption of fruit and vegetables is associated with a $16 \%$ lower risk of cardiovascular death $^{(27)}$. Our recent study showed that higher intake of fruit and vegetables explained $48 \%$ protective effect against CVD risk factors and the CVD risk $Z$ score was inversely related to higher fruit and vegetable intake (lowest quartile $Z$ score $=1.06 v$. highest quartile $Z$ score $=-1 \cdot 00)^{(15)}$. India, especially, has a prominent share of fruit and vegetable growth in the world ${ }^{(28)}$; however, this does not seem to be reflected in consumption. In the present study, fruit and vegetable consumption was very low and $90.9 \%{ }^{(15)}$ of the population consumed less than the WHO/FAO recommended value of $400 \mathrm{~g} / \mathrm{d}^{(7)}$. This is probably due to fruit and vegetables being unaffordable by a larger section of the population, leading to their export to other countries ${ }^{(29)}$.

Urbanisation stimulates improvements in infrastructure, including cold chains, which permit trade in perishable goods. As a result, city dwellers have a varied diet rich in animal proteins and fats, characterised by higher consumption of meat, poultry and dairy products ${ }^{(7)}$. However, the influence of urbanisation has not been reflected in the present study with regard to the average intake of meat and poultry being well within the recommend intake while fish intake was less than the recommend intake of $150 \mathrm{~g}$ of fish twice a week ${ }^{(30)}$ for the prevention of chronic diseases. This could possibly be due to the higher cost of these food items in the market today, in addition to the habitual consumption of these foods as an accompaniment to cereal-based staple meals. Moreover, religious practices also influence the intake as many days of the week are considered as strict vegetarian days in this region, and hence, this could be one of the possible explanations for dietary fat being within the recommended intake of $25-30 \%$ of energy ${ }^{(7)}$. Recent data from the National Family Health Survey 3 had shown that
Christians are more likely than any other religious group to eat chicken, meat, fish or eggs at least once a week. Jains and Sikhs rarely eat chicken, meat, fish or eggs, but they are more likely than persons in any other religious group to consume milk or curd. Jains are more likely than any other religious group to eat fruit at least once a week $^{(31)}$. However, in the present study, the majority of the participants belong to the Hindu religion and we did not have any Jain or Sikh participants. Hence, we are unable to offer further comparisons.

Dairy products consumption of $393.6 \mathrm{~g} / \mathrm{d}$ could possibly be explained by urbanisation and also coincides with higher milk production and availability in this country ${ }^{(32)}$. Evidence suggests that low-fat dairy foods may help reduce the risk of chronic diseases such as diabetes ${ }^{(33)}$, obesity ${ }^{(34)}$ and $\mathrm{CVD}^{(35)}$. In the present study, 3-4\% fat milk, the cheapest and readily available milk, was most commonly reported. We do recognise the potential for increasing consumption of low-fat milk as described in most dietary recommendations. However, in the Indian context, milk intake could be an important source for good bioavailable calcium, and it has, in fact, been shown to be associated with lower body fat ${ }^{(34)}$. This could particularly benefit Asian Indians, who have increased visceral fat and central obesity despite lower generalised obesity ${ }^{(36,37)}$.

Frequent consumption of sugar-rich and sweetened beverages has been shown to be associated with weight gain, obesity and increased risk of type 2 diabetes in the West $^{(17)}$. However, in the present study, the mean added sugar intake was well within the national recommended intake of $20-30 \mathrm{~g} / \mathrm{d}^{(30)}$ and also within the FAO/WHO recommendation of $<10 \%$ of total energy ${ }^{(7)}$. Sugar consumption was mainly in the form of added sugars in beverages such as coffee and tea compared to the West where it is mainly from sweetened beverages like soda and other soft drinks $^{(38)}$, which are mainly of high-fructose corn syrup ${ }^{(39)}$.

The strength of the present study is that a validated interviewer-administered FFQ, which is now considered a better method than a single $24 \mathrm{~h}$ recall, was used to measure the usual long-term intake of the population. Further, the sampling is representative of the overall population of Chennai. Moreover, the intake of major foods in the present study was similar to the findings of the pooled urban data of the National Nutrition Monitoring Bureau for ten states, which indicated the intake of cereals and millets $(\mathrm{RDA}=460 \mathrm{~g} / \mathrm{d})$ and green leafy vegetables $(\mathrm{RDA}=40 \mathrm{~g} / \mathrm{d})$ was less than the $\mathrm{RDA}^{(8)}$. Therefore, the results of the present study could be reasonably extrapolated to urban India, although there could be regional differences in terms of food choices within each food group (for example, North Indians usually eat wheat as their staple, whereas rice is the most common staple in South Indian diets, and both belong to the same food group - cereal grains). One of the limitations of the present study is that, being a cross-sectional one, it assessed the dietary intake of the population at a 
single time; prospective studies are obviously needed to identify the secular trend in the population. Another possible limitation is that there could be considerable underreporting of the income levels, particularly by those in the higher socio-economic group. This could skew the income distribution to the lower side and this could explain, for example, the lack of association of increased fruit and vegetable consumption with higher income groups in the present study. Moreover, the present study, conducted in 2005, reveals that 'Western foods' such as bread, potato and sugar added in soft drinks were not the main carbohydrate sources in the study population. The most frequently reported traditional food choices such as rice, $i d l i$, dosa and chapathi continue to form the main sources of carbohydrate in the present study population. Thus, there is an urgent need for periodical capture of the dietary preferences/patterns among Indians as the incidence of diet-related chronic diseases such as diabetes and CVD is on the rise. It is possible that in the next 5-10 years the dietary trends noted in the present study could drastically change.

In summary, in the present urban South Indian population the consumption of wholegrain cereals and millets is low, but a high consumption of refined grains is observed. Moreover, in addition to low intake of fish, the consumption of fruit and vegetables is also low. This could pose a serious concern, as these dietary preferences could be a potential risk factor for CVD. Income levels, prices, individual preferences and beliefs, cultural traditions, as well as environmental, social and economic factors all interact in a complex manner and are critical to the enhancement of the dietary profile of the population. These factors should be taken into consideration while planning mass education programmes on healthier eating food choices such as the introduction of wholegrain cereals in diets. Increasing the intake of healthier food choices like fruit and vegetables and fish in the present population is also urgently needed in order to reduce the burden of non-communicable diseases such as diabetes and CVD in the present study population.

\section{Acknowledgements}

The Chennai Urban Rural Epidemiological Study (CURES) fieldwork was supported by the Chennai Willington Corporate Foundation, Chennai, India. This is the 68th publication from the CURES - 68. All authors declare that they have no duality of interest associated with this manuscript. V.M. designed the study. G.R. and R.M.S. led the data collection. G.R. wrote the first draft of the manuscript and the statistical analysis and V.M. and V.S. rewrote the subsequent drafts. A.G. assisted in doing statistical analysis. G.R., R.M.S., A.G., R.S., P.V., V.S. and V.M. contributed to the interpretation of the data and all authors contributed and participated in the revision and final draft of the manuscript. They approved the final version and will take public responsibility for the content of the present paper.

\section{References}

1. Gupte MD, Ramachandran V \& Mutaktar RK (2001) Epidemiological profile of India: historical and contemporary perspectives. J Biosci 26, 437-464.

2. Unwin N, Whiting D, Gan D et al. (editors) (2009) Diabetes Atlas, 4th ed., p. 12. Brussels: International Diabetes Federation.

3. Reddy KS, Shah B, Varghese C et al. (2005) Responding to the threat of chronic diseases in India. Lancet $\mathbf{3 6 6}$, $1746-1751$.

4. Mohan V (2004) Why are Indian more prone to diabetes? I Assoc Physicians India 52, 468-474.

5. Vimaleswaran KS, Radha V \& Mohan V (2006) Thr54 allele carriers of the Ala54Thr variant of FABP2 gene have associations with metabolic syndrome and hypertriglyceridemia in urban South Indians. Metabolism 55, 1222-1226.

6. Mohan V, Gokulakrishnan K, Deepa R et al. (2005) Association of physical inactivity with components of metabolic syndrome and coronary artery disease - the Chennai Urban Population Study (CUPS no. 15). Diabet Med 22, 1206-1211.

7. World Health Organization (2003) Diet, Nutrition and the Prevention of Chronic Diseases. Joint WHO/FAO Expert Consultation. WHO Technical Report Series no. 916. Geneva: WHO.

8. National Institute of Nutrition, Indian Council of Medical Research (2000) 25 Years of the National Nutrition Monitoring Bureau: 1972-1997. Hyderabad: NIN, ICMR.

9. National Sample Survey Organization (2000) Indian Government: Food Consumption Surveys. New Delhi: $\mathrm{NSSO} /$ Government of India.

10. Popkin BM, Horton S, Kim S et al. (2001) Trends in diet, nutritional status, and diet-related non-communicable diseases in China and India: the economic costs of the nutrition transition. Nutr Rev 59, 379-390.

11. Deepa M, Pradeepa R, Rema M et al. (2003) The Chennai Urban Rural Epidemiology Study (CURES) study design and methodology (urban component) (CURES-I). I Assoc Physicians India 51, 863-870.

12. Michels KB, Welch AA, Luben R et al. (2005) Measurement of fruit and vegetable consumption with diet questionnaires and implications for analyses and interpretations. Am J Epidemiol 161, 987-994.

13. Sudha V, Radhika G, Sathya RM et al. (2006) Reproducibility and validity of an interviewer administered semiquantitative food frequency questionnaire to assess dietary intake of urban adults in southern India. Int J Food Sci Nutr 57, 481-493.

14. Radhika G, Van Dam RM, Sudha V et al. (2009) Refined grain consumption and the metabolic syndrome in urban Asian Indians (Chennai Urban Rural Epidemiology Study 57). Metabolism 58, 675-681.

15. Radhika G, Sudha V, Sathya RM et al. (2008) Association of fruit and vegetable intake with cardiovascular risk factors in urban south Indians. Br J Nutr 99, 398-405.

16. Bamji MS, Krishnaswamy K \& Brahmam GNV (editors) (2009) Textbook of Human Nutrition, 3rd ed. New Delhi: Oxford \& IBH Publishing Co. Pvt Ltd.

17. Esmaillzadeh A, Kimiagar M, Mehrabi Y et al. (2007) Dietary patterns, insulin resistance, and prevalence of the metabolic syndrome in women. Am J Clin Nutr 85, 910-918. 
18. Jiang BQ, Zhong PH \& Cheng XB (2007) Investigation of health and nutrition status of middle-aged and old residents in the urban district of Chongqing. Asia Pac J Clin Nutr 16, Suppl. 1, S17-S21.

19. Radhika G, Ganesan A, Sathya RM et al. (2009) Dietary glycemic load and high density lipoprotein cholesterol among south Indian adults. Eur J Clin Nutr 63, 413-420.

20. Mohan V, Radhika G, Sathya RM et al. (2009) Dietary carbohydrates, glycaemic load, food groups and newly detected type 2 diabetes among urban Asian Indian population in Chennai, India (Chennai Urban Rural Epidemiology Study 59). Br J Nutr 102, 1498-1506.

21. Food and Agriculture Organization of the United Nations (2006) The Double Burden of Malnutrition: Case Studies from Developing Countries - India. FAO Food and Nutrition Paper no. 84. Rome: FAO.

22. Mohan V, Shanthirani S, Deepa R et al. (2001) Intra-urban differences in the prevalence of the metabolic syndrome in southern India - The Chennai Urban Population Study (CUPS no. 4). Diabet Med 18, 280-287.

23. National Sample Survey Organization (2005) Ministry of Statistics and Programme Implementation. NSS 60th Round, Household consumer expenditure in India: Jan-Jun 2004. Press Information Bureau, Government of India. http:// www.mospi.nic.in/505_nss_press_note_jan-june04.htm

24. Schmidhuber J \& Shetty P (2005) The nutrition transition to 2030. Why developing countries are likely to bear the major burden. Acta Agric Scand. C Econ 2, 150-166.

25. Toriyama K, Heong KL \& Hardy B (editors) (2005) Rice is Life: Scientific Perspectives for the 21st Century. Proceedings of the World Rice Research Conference held in Tokyo and Tsukuba, Japan, 4-7 November 2004. Los Baños, Philippines: International Rice Research Institute \& Tsukuba: Japan International Research Center for Agricultural Sciences.

26. Bachman JL, Reddy J, Subar A et al. (2008) Sources of food group intake among US population, 2001-2002. J Am Diet Assoc 108, 804-814.
27. Dauchet L, Amouyel P, Hercberg S et al. (2006) Fruit and vegetable consumption and risk of coronary heart disease: a meta-analysis of cohort studies. J Nutr 136, 2588-2593.

28. Kaul GL (1998) Fruit and vegetable production in India. NFI Bull 19, 5-8.

29. Shetty PS (2002) Nutrition transition in India. Public Health Nutr 5, 175-182.

30. Ghafoorunissa \& Kirshnaswamy K (2000) Diet and Heart Disease, p. 37. Hyderabad: National Institute of Nutrition.

31. International Institute for Population Sciences and Macro International (2007) National Family Health Survey (NFHS-3), 2005-06: India, vol. I. Mumbai: IIPS.

32. Department of Animal Husbandry, Dairying \& Fisheries, Ministry of Agriculture, Government of India (2010) Milk production in India. http://www.nddb.org/statistics/ milkproduction.html

33. Anastassios GP, Joseph L, Hu FB et al. (2007) The role of vitamin $\mathrm{D}$ and calcium in type 2 diabetes. A systematic review and meta-analysis. J Clin Endocrinol Metab 92, 2017-2029.

34. Zemel MB, Shi H, Greer B et al. (2000) Regulation of adiposity by dietary calcium. FASEB J 14, 1132-1138.

35. Jacqmain M, Doucet E \& Despres JP (2003) Calcium intake, body composition, and lipoprotein-lipid concentrations in adults. Am J Clin Nutr 77, 1448-1452.

36. Raji A, Seely EW, Arky RA et al. (2001) Body fat distribution and insulin resistance in healthy Asian Indians and Caucasians. J Clin Endocrinol Metab 86, 5366-5371.

37. Anjana M, Sandeep S, Deepa R et al. (2004) Visceral and Central abdominal fact and anthropometry in relation to diabetes in Asian Indians (CURES-7). Diabetes Care 27, 2948-2953.

38. Bleich SN, Wang YC, Wang Y et al. (2009) Increasing consumption of sugar-sweetened beverages among US adults: 1988-1994 to 1999-2004. Am J Clin Nutr 89, 372-381.

39. Vuilleumier S (1993) Worldwide production of highfructose syrup and crystalline fructose. Am J Clin Nutr 58, Suppl. 1, S733-S736. 